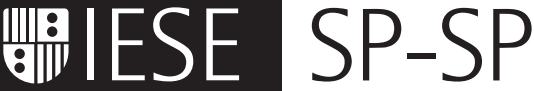

University of Navarra

\section{Working Paper}

WP No 605

July, 2005

THE ORGANIZATION AND PERFORMANCE EVALUATION

OF R\&D PROJECTS IN A DYNAMIC ENVIRONMENT

\author{
Bruno Cassiman* \\ Chiara Di Guardo** \\ Giovanni Valentini***
}

* Professor of General Management, IESE

* Professor, University of Cagliari

*** Doctoral Candidate, IESE 
The Public-Private Center (SP-SP) is a Research Center based at IESE Business School. Its mission is to develop research that analyses the relationships between the private and public sectors primarily in two areas: regulatory (the effects of regulation on private economic activity) and contractual (the total or partial transfer of public services to the private sector). Research results are disseminated through publications, conferences and colloquia. These activities are aimed to foster cooperation between the private sector and public administrations, as well as the exchange of ideas and initiatives.

The sponsors of the SP-SP Center are the following:

- Accenture

- Ajuntament de Barcelona

- Official Chamber of Commerce, Industry and Navigation of Barcelona

- BBVA

- Diputació de Barcelona

- ENDESA

- Garrigues, Abogados y Asesores Tributarios

- Catalan Government (Generalitat de Catalunya)

- Grupo MSD

- Telefónica, S.A.

- T-Systems

- VidaCaixa

The content of this publication reflects the conclusions and findings of the individual authors, and not the opinions of the Center's sponsors. 


\title{
THE ORGANIZATION AND PERFORMANCE EVALUATION OF R\&D PROJECTS IN A DYNAMIC ENVIRONMENT
}

\begin{abstract}
Faster technological development, shorter product life-cycles, and more intense global competition have transformed the current competitive environment for most firms. This new competitive landscape forces organizations to actively acquire knowledge, as a firm's competitive advantage is now more dependent on continuous knowledge development and enhancement. Therefore, knowledge has become a central theme in strategic management. Against this background, we argue that the knowledge characteristics of $R \& D$ projects are fundamental variables to explain governance decisions. Drawing upon the case of STMicroelectronics, we provide evidence that partnering or contracting with universities for innovation is common practice for developing new -original-knowledge, as opposed to applying existing knowledge, for solving a problem. However, the firm is more reluctant to partner, especially with another firm, when this knowledge directly enhances its competitiveness. Moreover, we find that $\mathrm{R} \& \mathrm{D}$ project performance is a bi-dimensional construct. One dimension picks up project efficacy and immediate benefits, while the other includes learning and long-term benefits. Though spanning firm boundaries for innovation does not seem to have appreciable effects on perceived project efficiency, it nonetheless brings about intertemporal benefits related to learning and capabilities development. In a dynamic environment, building knowledge may be more important than protecting it. Thus, an open innovation process may be an exceptionally effective way to build and develop the firm's technological future.
\end{abstract}

Keywords: Innovation strategy, R\&D project organization, R\&D project performance, open innovation 


\section{THE ORGANIZATION AND PERFORMANCE EVALUATION OF R\&D PROJECTS IN A DYNAMIC ENVIRONMENT ${ }^{1}$}

\section{Introduction}

In recent years, the concept of "open innovation" innovation strategy discussions. Successful innovation depends on the development and integration of new knowledge in the innovation process. To innovate, in addition to doing own research and development, firms may engage in the acquisition of external knowledge and technology, using a variety of possible agreements. Being a world-class innovator today thus requires not only great scientists and research facilities, but also a suitable process for managing these different technology and knowledge sources. Still, despite the many benefits of employing open innovation strategies, developing a successful program in this direction can pose several organizational challenges.

The main issues we tackle in this article are: How does a firm-level open innovation strategy translate to lower organizational levels - in particular the individual project and activity levels? What is the impact of an open innovation strategy on technological performance and how do lower organizational levels contribute to firm-level performance? We address these research questions drawing upon the organization and innovation literature. As prior literature has made only small inroads into an understanding of some of these relevant issues, we elaborate the case of STMicroelecronics (ST), the largest microelectronics company in Europe, to gain a deeper understanding of the relationship between the organization of innovation activities and performance.

We adopt the R\&D project as the key level of analysis and explore the organization and performance of 62 projects carried out in one of the biggest ST research centers in Europe between 1998 and 2003. The study highlights the relevant project and activity

\footnotetext{
${ }^{1}$ The authors would like to thank Giuseppe Ferla and Cristina Di Gesú of STMicroelectronics for their time and the access provided to data on R\&D projects. The authors are grateful for the comments received from the participants at the EIASM Workshop on "Coopetition strategy: toward a new kind of interfirm dynamics?" (Catania) and acknowledge financial support from the European Commission Key Action "Improving the socio-economic knowledge base" through contract No. HPSE-CT-2002-00146, the Public-Private Sector Research Center at IESE Business School and the Spanish Government research grant (SEC 2003-08282). Bruno Cassiman is also a senior researcher in the Steunpunt O\&O, financed by the Flemish government. Giovanni Valentini, PhD Candidate, is corresponding author.

${ }^{2}$ Chesbrough, H.W. (2003). Open Innovation. Boston: Harvard Business School Press; Linder, J., Jarvenpaa, S. and Davenport, T. (2003)."Toward an Innovation Sourcing Strategy”. Sloan Management Review, 44(4): 43-49; Rigby, D., and Zook, C. (2002). "Open-market innovation”. Harvard Business Review, October, 80-89.
} 
characteristics that drive the organization of $R \& D$ projects and activities. Furthermore, we find that a project's performance should be measured along the orthogonal dimensions of efficiency and learning in order to capture the total firm level innovative performance, which includes the project's short term performance and the long term performance across different projects and activities. In sum, we show how one firm has succeeded in organizing and profiting from an open innovation strategy by recombining resources through both internal development and collaboration and cooperation. We build on the findings from our case study to develop a conceptual framework of the relevant variables which need to be taken into account for designing a suitable open innovation strategy at the project and activity levels.

This article starts off by providing some background about the relationship among different organizational levels within the innovation process. Next, we discuss our empirical setting. We then attempt to disentangle the open innovation process and discuss how to model the relationship between project organization and project characteristics. In the final part of the paper, we discuss the performance implications of an open innovation strategy.

\section{The innovation process}

The innovation process, by which we mean the process through which firms aim at creating new valuable knowledge and strive to capture the value stemming from it, involves factors and processes at the industry, organization, project, and individual activity levels. Yet most innovation research tends to focus at one level of analysis (oftentimes the firm level) and only rarely considers different levels and the connections between these different levels.

Analysts and managers have long recognized that innovation can arise by using both internal and external sources and have documented the advantages and the disadvantages of an open innovation strategy, chiefly at the firm level. ${ }^{3}$ Arguments emphasizing the benefits of external knowledge acquisition assume that many critical capabilities reside outside the boundaries of the firm and that appropriation problems are minimal. In these settings, performance is directly tied to the ability to identify, isolate, and solve a specific set of independent technical problems. In contrast, arguments extolling the benefits of internal development assume that the most valuable capabilities reside within the firm and that appropriation problems are significant. In such case, the principal advantage of internal organization derives from the ability to provide enhanced information transfer and coordination across activities within the knowledge production system, therefore implying that performance is principally driven by second- and higher-order interactions among a set of value-chain activities. ${ }^{4}$

The concept of absorptive capacity enriches this picture, suggesting that the impact of internal and external technology on firm performance is not independent, and that firms' ability to profit from external know-how is largely a function of their level of prior related knowledge. ${ }^{5}$ Furthermore, recent studies provide mounting evidence about the potential for

\footnotetext{
${ }^{3}$ Nagarajan A. and Mitchell, W. (1998). "Evolutionary diffusion: internal and external methods used to acquire encompassing, complementary and incremental technological changes in the lithotripsy industry". Strategic Management Journal, 19: 1063-1077; Veugelers, R. and Cassiman, B. (1999). "Make and buy in innovation strategies: Evidence from Belgian manufacturing firms", Research Policy, 28: 63-80.

${ }^{4}$ De la Mothe, J. and Link, A.N. (2002) (eds.). Networks, Alliances, and Partnerships in the Innovation Process. Boston: Kluwer Academic.

${ }^{5}$ Cohen, W. and Levinthal, D. (1990). "Absorptive capacity: A new perspective on learning and innovation". Administrative Science Quarterly, 35: 128-152.
} 
combining internal and external sourcing modes as complementary innovation activities. ${ }^{6}$ External technological know-how acquisition may stimulate rather than substitute own R\&D activities, and vice versa, thus determining a positive effect on the innovation performance.

Although there is some evidence at the firm level to support the positive relationship between the combination of innovation activities and performance, the factors that explain these phenomena at a micro level are still not clear. Little is known about how variables at one level of analysis influence innovation at another level, or how variables at different levels of analysis interact to determine the extent and type of resulting innovation.

We begin to unravel this complex system by studying drivers and consequences of an open innovation strategy at the project and activity levels. While each organizational level undoubtedly experiences some relevant factors and drivers that act only at that specific layer, it is undeniable that firm, project, and activity levels are deeply interrelated (see Figure 1). In the first place, higher levels of the organization offer opportunities and impose constraints on lower levels. A proper organizational design of the innovation process will maximize the likelihood that decision makers have 1) the relevant information and resources to make good decisions and 2) the incentives to use information and resources productively. And second, the success of a firm's open innovation strategy is built and relies upon the performance of lower organizational levels in the innovation process. $R \& D$ projects produce some positive externalities appropriable at the firm level, and a project's activities bring about positive externalities enjoyed at the project level - across projects or across activities within the same project.

Figure 1. Organizational levels

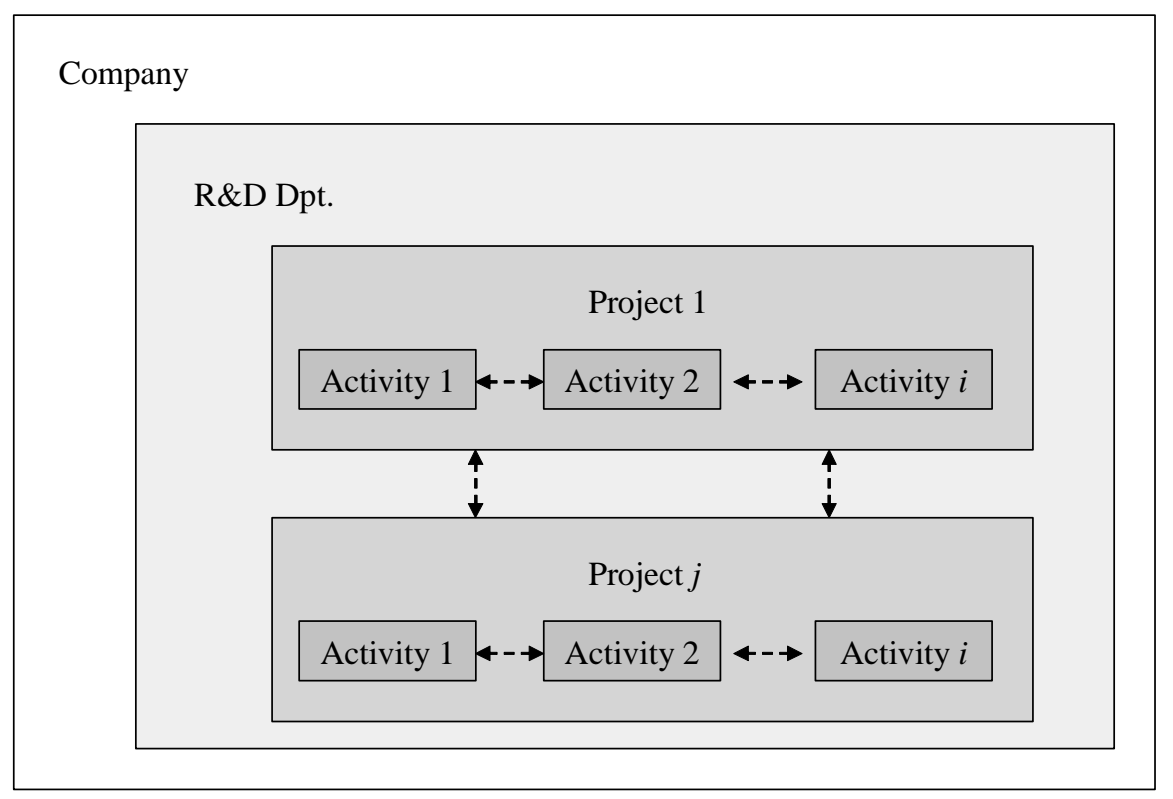

Moreover, were one to conceive strategy as a deliberate process, it would be clear that a deliberate, analytically formulated innovation strategy at the firm level can only be implemented through a stream of $R \& D$ projects. By the same token, if strategy were an

\footnotetext{
${ }^{6}$ Arora, A. and Gambardella, A. (1990). "Complementarity and external linkages: the strategies of the large firms in biotechnology”. Journal of Industrial Economics, 38: 361-379; Cassiman, B. and Veugelers, R. (2004). "In search of complementarity in the innovation strategy: Internal R\&D \& external knowledge acquisition”. Working paper, IESE Business School, Barcelona.
} 
emergent process that evolves from the cumulative impact of operating decisions taken by management, the ideas and the results of $R \& D$ projects that determine the stream of products that flowed into the marketplace are amongst the most tangible manifestation of what the firm's innovation strategy actually has been. Therefore, any comprehensive study of the innovation strategy of a firm should include a careful analysis at the activity and project level.

As said, the goal the innovation process should pursue is to create new knowledge and capture the value stemming from it. To this end, two key decisions have to be faced: which projects to carry out and how to organize the projects themselves. Here, we will focus on the latter decision, with particular reference to an open innovation process. The former decision is a strategic choice generally faced at the firm level. It certainly is of paramount importance, but it goes beyond the question we are tackling in this paper: to open or not to open the innovation process.

We carefully examine the innovation process of STMicroelectronics, and thereby provide evidence and potential guidance for other firms when opening up their innovation strategy.

\section{STMicroelectronics ${ }^{7}$}

STMicroelectronics (ST) was created in 1987 through the merger of SGS Microelettronica of Italy and Thomson Semiconducteurs of France, with the aim of becoming a world leader in the semiconductor industry. The microelectronic market place (or semiconductor industry) includes the producers of integrated circuits and miniaturized electronic components used in the automotive, telecommunications, computer sectors and in the industrial and consumer fields.

Since its formation, ST has pursued an aggressive growth strategy, investing heavily in R\&D, forging strategic alliances with blue-chip customers and academia, building up an integrated presence in major economic regions, and honing one of the world's most efficient manufacturing operations. ST has consistently grown faster than the semiconductor industry as a whole and has been one of the world's Top Ten semiconductor suppliers since 1999.

In 2004, ST's net revenues were US $\$ 8,760$ million and net earnings were US\$601 million. The group currently has more than 40,000 employees, 12 advanced R\&D centers, 18 production plants and 71 commercial offices in 26 countries. With advanced R\&D centers strategically located in Italy, France, USA, Canada, UK, India and Singapore, the company can draw upon a broad range of proprietary, leading edge technologies.

The Company's market leadership is spread across many fields. For example, according to independent sources, ST is the world's leading supplier of wireless ASICs, computer peripheral ASICs, automotive ASSPs, MPEG-2 decoder ICs, digital consumer ASSPs, and ICs for set-top boxes. It is also the world's second largest supplier of smart card and xDSL chips, number three for discrete products and all automotive semiconductors, and ranked fourth in NOR Flash ICs.

ST strategy toward its global operation consists of a systemic and holistic approach that envisions the foreign affiliates as a part of a network of interrelated activities, designed

\footnotetext{
${ }^{7}$ The main sources for this section are ST's website, official presentations and personal interviews with the key players.
} 
to promote the interest of the multinational in toto. This type of approach promotes vertical specialization, where different stages of the value-added chain of a particular product are undertaken in different locations.

ST has maintained an average R\&D expenditure of more than $16 \%$ of revenue over the last three years, and an average of more than $13 \%$ of revenue from the date of the company's creation, compared to an industry average of less than $11 \%$. In 2003, ST spent approximately US $\$ 1.2$ billion on R\&D, which was slightly more than $17 \%$ of its revenues. That effort produced 663 patent applications in 2003 alone, maintaining ST's track record as one of the industry's most prolific inventors.

ST is also active in numerous collaborative research projects worldwide. As a matter of fact, the effectiveness of the partnerships ST has forged with many leading participants in the global semiconductor industry has been a key contribution to its success. These include strategic alliances with key customers, technology development alliances with customers and competitors alike, development alliances with major equipment, materials and CAD suppliers, and partnerships with multinational R\&D organizations, universities, and research institutes.

ST's dynamic innovation strategy is also the result of two critical industry features. First, the semiconductor industry is highly cyclical. It is subject to rapid technological change and has been subject to significant economic downturns at various times, characterized by diminished product demand, accelerated erosion of average selling prices, and excess production capacity. Likewise, the industry also periodically experiences increased demand and production capacity constraints. Roughly every four or five years, new technological innovations are introduced into the market (e.g. production of DRAM, SRAM, Flash, System-on-Chip, etc.), and these determine a growth in demand tied to the development of new markets and new applications (increasing demands on PC memory, DVD players and decoders, mobile telephones, PDAs and other handheld devices, etc.). Second, during the past ten years or so, the world's leading semiconductor manufacturers pursued the goal of developing System-on-Chip (SoC) technologies, which integrate different functions in a single chip, aiming for total integration of the system. The needs of the future -mobility, multimediality, security, and mass memory- are linked with the capacity to integrate blocks of pre-developed circuits (blocks of Intellectual Property-IP) in a SoC. The SoC approach requires the integrating technology of semiconductor manufacturers -the silicon know how- and the system know how typical of the electronic devices producers. The uncertainty due to market cyclicality and the complementary technological capabilities needed therefore favor the potentiality of an open innovation strategy.

\section{Research methods and data collection}

Faster technological development, shorter product life-cycles, and more intense global competition have transformed the current competitive environment for most firms. This new competitive landscape forces organizations to actively acquire knowledge since a firm's competitive advantage is now more dependent on continuous knowledge development and enhancement. Therefore, knowledge has become a central theme in strategic management. Along these lines, we argue that the knowledge characteristics of R\&D projects are fundamental variables to explain governance decisions.

This study offers an unusually detailed examination of R\&D projects' knowledge attributes, organization and performance. By focusing on one firm, we were able to study 
remarkably fine-grained data. We developed a database that contains information about 62 R\&D projects that got started between 1998 and $2003 .{ }^{8}$ As a matter of internal procedure, all these projects are classified by internal and external experts along four dimensions that identify each project's knowledge content along different dimensions. First, on a 1-to-3 scale, the novelty and originality of the knowledge developed in the project as compared to the state of the art in the specific technological domain is evaluated. Second, again on a 1-to-3 scale, the (immediate, expected) utility of the knowledge for achieving product or process innovations that may enhance the firm's competitiveness is assessed. This measure clearly relates to the project's strategic value. And third, on a 1-to-4 scale, the ease of industrialization and transferability to manufacturing of the project's results is evaluated. This measure could be used as a proxy for the tacitness of the project's knowledge. Tacit knowledge is knowledge that cannot readily or easily be written down. Projects with high ease of industrialization typically have more highly codified knowledge. Finally, we constructed a measure of the proportion of the project's activities aimed at developing new knowledge (as opposed to applying it), which we believe may constitute an indicator of the basicness of the project. These measures have been constructed based on standardized internal documents about all $R \& D$ projects at the ST site.

In addition, we gathered data on the performance of 39 out of 62 projects (those that were already completed or sufficiently advanced) through a short questionnaire administered to the project managers. ${ }^{9}$ More specifically, project managers were asked to evaluate the extent to which: a) the technical outcome of the project had met expectations, b) the project had kept to schedule, c) the tasks had been accomplished, d) the project was on or near budget, e) the project as a whole had outperformed similar projects carried out in the past, f) potential new applications of the technology / outcome being developed had been recognized during the project, and g) new knowledge had been acquired that they had already applied or were confident they would apply in other projects.

\section{Types of ST R\&D projects}

It may be helpful to start by briefly discussing the nature and characteristics of the projects in our sample. The projects in our sample have an average length of 31.5 months and require 8.2 man-years to complete. Seven different strategic lines of innovation can be explored: technological and design platforms; advanced applications, new devices, and optoelectronic integrated circuits; memories and system on chip; nanotechnologies; new materials; bioelectronics, health; new computational models. A project idea may have originated externally (in a university or in a firm) or internally (in the same R\&D division in which the projects are carried out, in another R\&D division, at subsidiary central $R \& D$, or in the corporate $\mathrm{R} \& \mathrm{D}$ unit). Projects may also have different clients, internal and/or external. An analysis of the correlation matrix between project origin and clients ${ }^{10}$ highlights the following results. First, central R\&D is the only "originator" that has a strong correlation with the fact of being also a client of a project $(r=0.70)$. Second, projects that originate from a university are positively correlated with having corporate R\&D as their client $(r=$ 0.40 ). This is consistent with the stylized fact that corporate $R \& D$ is generally closer to science. ${ }^{11}$ Third, projects that originated in the same R\&D division where they were carried

\footnotetext{
${ }^{8}$ Each project consists on average of about 20 separate activities, for which we have additional information leading to an activity level database of more than 1200 observations.

9 The questions are based on the items of the scale developed in Sicotte, H. and Langley, N. (2000). "Integration mechanisms and R\&D project performance". Journal of Engineering and Technology Management, 17: 1-37; and in Hall, B.H., Link, A.N. and Scott, J.T. (2003). "University as research partner". Review of Economics \& Statistics, 85: 485-491 to assess R\&D project performance.

${ }^{10}$ The correlation matrix is not reported here but is available upon request from the authors.

${ }^{11}$ Hauser, J. (1998). "Research, development, and engineering metrics”. Management Science, 44: 1670-1689.
} 
out are negatively correlated with having a customer external to the firm $(r=-0.51)$. Thus, units' autonomous projects seem unlikely to be market-oriented. And finally, not surprisingly, projects that originated outside ST are positively correlated with having external clients $(r=0.53)$.

Of the projects in our sample, $90 \%$ span the boundaries of ST, having at least one partner ${ }^{12}$ or one contractor, while $29 \%$ have both. Table 1 reports aggregate data regarding partners and contractors.

Table 1. Descriptive data on R\&D project Partners and Organization

\begin{tabular}{|l|c|c|c|c|}
\cline { 2 - 5 } \multicolumn{1}{c|}{} & \multicolumn{4}{c|}{ Type of Organization ${ }^{\mathrm{a}}$} \\
\cline { 2 - 5 } \multicolumn{1}{c|}{} & \multicolumn{2}{c|}{ Partnership } & \multicolumn{2}{c|}{ Contract } \\
\hline $\begin{array}{l}\text { Spanning the } \\
\text { boundaries of the } \\
\text { firm with }\end{array}$ & $\begin{array}{c}\text { Conditional on } \\
\text { having Partnership }\end{array}$ & $\begin{array}{c}\text { Conditional on } \\
\text { having Contract }\end{array}$ \\
\hline University & $37 \%$ & $59 \%$ & $40 \%$ & $70 \%$ \\
\hline Research Center & $21 \%$ & $34 \%$ & $31 \%$ & $53 \%$ \\
\hline Firm & $42 \%$ & $69 \%$ & $8 \%$ & $13 \%$ \\
\hline
\end{tabular}

${ }^{a}$ Partnerships and Contracts can have different partners simultaneously.

\section{R\&D project characteristics and organization}

We now focus attention on R\&D project characteristics and organization. The case of ST Microelectronics has helped us to understand that to manage the innovation process effectively, a clear understanding of the characteristics of the knowledge assets involved is needed.

Four important dimensions of the knowledge involved in $R \& D$ projects affect project organization in different ways.

A first relevant dimension of a project's knowledge is its basicness, i.e. its relatedness to fundamental research. On the one hand, the basicness of the project should favor the use of external sourcing. Firms may have scarce economic incentive for investments in basic research. Uncertainty about the results and appropriability hazards are two relevant reasons for such lack of incentive. These same factors may also drive the failure of a market for knowledge. Cooperation in R\&D may mitigate these obstacles. Firstly, by cooperating with other economic subjects (such as universities and research centers) firms may share risks and costs. ${ }^{13}$ Secondly, cooperation may facilitate the internalization of knowledge spillovers. Moreover, by way of cooperation firms may learn

\footnotetext{
${ }^{12}$ An external actor is defined to be a partner when it formally presents the project together with ST for external financing and is formally co-responsible for results.

${ }^{13}$ Miotti, L. and Sachwald, F. (2003). "Cooperative R\&D: Why and with whom? An integrated framework of analysis". Research Policy, 32: 1481-1499; Veugelers, R. and Cassiman, B. (2005). "R\&D Cooperation between Firms and Universities: Some empirical evidence from Belgium", forthcoming in The International Journal of Industrial Organization.
} 
and build capabilities they would not get by simply contracting out their needs. A large literature suggests, for example, that universities and industrial firms have complementary resources and skills. ${ }^{14}$ While universities have access to intellectual resources and a worldclass basic research infrastructure, industrial firms usually have practical expertise, financial resources, internship opportunities for students, and employment opportunities for graduates.

A second important dimension is the novelty of a project's knowledge relative to the firm's existing knowledge base. Novelty increases the propensity to open the boundaries of the project. Firms are more likely to look for complementary external resources when they are moving away from their knowledge domain, looking for partners with more productive resources given a specific task. However, this may be true only up to a certain point. Received theory argues that when melting different knowledge bases, a degree of knowledge relatedness is needed in order to benefit from absorptive capacity, but also that if knowledge bases are either too similar or too different, there is no room for valuable external contributions to innovation.

Yet, the higher the basicness and the novelty of a project, the higher its uncertainty. Therefore, internal development could provide a better means to respond to unanticipated contingencies (or opportunities) over the course of the project. While technically novel projects need creative problem solving, they may also cause unwanted delays and cost overruns (i.e. increase outcome uncertainty): hierarchical governance may be needed to guard against these hazards. Also, internal development relieves firms from fully specifying contractual arrangements, whose terms are less obvious and known when information is new and uncertain. In addition, the more basic and novel the project, the lower the ability to assess its outcomes. Uncertainty in performance measurement creates a higher incentive for opportunistic behavior by partners, and thus should make internal development more likely.

Contractual hazards and the incentive of the external actors involved in an R\&D project to behave opportunistically are higher when the expected pay-off of such behavior is higher. The expected pay-off depends both on a) the intrinsic potential value of the results of the project and on b) the probability of being able to capture the value itself. These, in turn, depend on two important project knowledge dimensions: strategic importance and codifiability. Projects whose knowledge is of relevant strategic value may increase the incentive for partners to cheat and perhaps engage in a "learning race" and avoid sharing the developed knowledge. It is more likely to be so when the external actor involved is a firm: in Europe, universities and research institutes do not generally have commercial activities. In addition, projects of strategic importance more likely imply commitments and specific investments. ${ }^{15}$ The more specialized a resource, the lower its value in alternative uses, and the higher the probability of being held-up by a partner. Therefore, internal development should be preferred. ${ }^{16}$ Nonetheless, it is in highly strategic projects that it becomes evident how no single firm has all the capabilities necessary for success. As firms may lack competence in a number of technological fields, cooperation with other enterprises creates the necessary complementary inputs and enables them to capitalize on economies of scope.

\footnotetext{
${ }^{14}$ Dasgupta, P. and David, P.A. (1994). "Toward a new economics of science". Research Policy, 23:487-521. Graff, G., Heiman, A. and Zilberman, D. (2002). "University research and offices of technology transfer". California Management Review, 45(1): 88-115.

${ }^{15}$ Ghemawat, P. (1991). Commitment. The Dynamics of Strategy. New York: The Free Press.

16 Robertson, T.S. and Gatignon, H. (1998). "Technology development mode: A transaction cost conceptualization". Strategic Management Journal, 19: 515-531; Williamson, O.E. (1985). Economic Institutions of Capitalism. New York: The Free Press.
} 
Finally, the extent to which the knowledge of a project is codifiable as opposed to tacit constitutes the fourth relevant knowledge dimension. ${ }^{17}$ When a project's knowledge is predominantly codified, it is easier to "steal" project outcomes and the potential partner has less need to share its tacit competencies, thus making opportunistic behavior more probable. Moreover, a potential partner is more likely to imitate the internal competencies a firm invests in the project. However, researchers contend that a key advantage of organizations is their ability to economize on communication through a common code. When the knowledge to be shared is tacit, the cost of communicating and coordinating with an external partner is higher, and so internal organization becomes more efficient.

\section{Optimal project organization}

There are several possible governance structures that can be employed for organizing $\mathrm{R} \& \mathrm{D}$ projects. The analysis focuses on three of them: internal development, cooperation with a third party, and contracting out. Cooperation represents an intermediate -non market, bilateral- hybrid governance mechanism between market and hierarchies where both parties are jointly responsible for the project outcome. Contracting implies that a partner commits to deliver output for some activities in the project. Each organizational form has specific advantages and drawbacks. Related literature suggests that the use of external agreements is favored to quickly access fresh knowledge and benefit from complementary capabilities. But the achievable benefits may be offset by the risk of low appropriability because of leakage and opportunistic behavior.

The case of STMicroelectronics helps to shed some new light on this issue. To the best of our knowledge, our data set is the first that allows consideration of contemporaneously different forms of governance and different partners / contractors (i.e. universities vs. firms).

Table 2 reports the average value of project knowledge attributes across different organizational forms, and the results of a t-test for differences in means. We argue that a project's organizational form depends on its knowledge attributes. We find that the more basic a project, i.e. the more it tends to develop new knowledge as opposed to applying earlier knowledge, the more likely it is that external capabilities are sought. Projects conducted in cooperation with universities ${ }^{18}$ are significantly more basic $(p<0.01)$, as are those conducted in cooperation with a firm $(p<0.05)$. Thus, despite the risk of opportunistic behavior and the uncertainty involved, basic projects are primarily carried out through cooperation to take advantage of external capabilities and seize learning opportunities. Also, projects conducted in cooperation are characterized by significantly more codified knowledge ( $p<0.1$ for universities and $p<0.05$ for firms). This relates to the lower cost of communications between partners.

Yet the search for external resources has to be balanced with transaction cost considerations: when project knowledge has a high strategic value, internal development or simple contracting of some specific activities is preferred. On average, projects conducted in cooperation with firms and universities show, in fact, a significantly lower strategic importance (respectively, $p<0.01$ and $p<0.1$ ). Conversely, projects in which some activities are contracted out to universities have a higher strategic importance $(p<0.01)$. In

\footnotetext{
${ }^{17}$ Winter, S. (1997). "Knowledge and competence as strategic assets". In: Teece, D.J. (ed.) The Competitive Challenge, Cambridge, MA: Ballinger, 159-184.

${ }_{18}$ Given the small number of observations and without loss of generality, in the following analyses we will lump together cooperation with universities and research centers.
} 
this case, both the governance form and the partner's characteristics may mitigate the risk of leakage.

Table 2. Project knowledge attributes depending on project governance form: Means and t-test for difference in means

\begin{tabular}{lcccc}
\hline & $\begin{array}{c}\text { Dummy for cooperation in } \\
\text { projects with a university }\end{array}$ & $\begin{array}{c}\text { Dummy for cooperation in } \\
\text { projects with a firm }\end{array}$ \\
\hline Basicness & 1 & 0 & 1 & 0 \\
Novelty & $0.92^{* *}$ & 0.75 & $0.90^{*}$ & 0.76 \\
Strategic importance & 2.10 & 1.93 & 1.95 & 2.03 \\
Codifiability & $2.10^{\dagger}$ & 2.43 & $2.00^{* *}$ & 2.50 \\
Cost & $2.73^{\dagger}$ & 2.17 & $2.82^{*}$ & 2.10 \\
& $8.50^{\dagger}$ & 10.83 & 9.73 & 9.93 \\
\hline & Dummy for contracting in & Dummy for contracting in \\
& projects with a university & projects with a firm \\
\hline Basicness & 1 & 0 & 1 & 0 \\
Novelty & 0.86 & 0.76 & 0.90 & 0.81 \\
Strategic importance & $2.21^{* * *}$ & 1.74 & 2.25 & 1.98 \\
Codifiability & $2.52^{* *}$ & 2.00 & 2.75 & 2.25 \\
Project cost & 2.55 & 2.22 & 2.00 & 2.44 \\
\hline
\end{tabular}

${ }^{\dagger} p<.10 \quad{ }^{*} p<.05 \quad{ }^{* *} p<.01 \quad{ }^{* * *} p<.001$

Our results highlight how, in a dynamic environment, building knowledge may be more important than protecting it. While it is important for a firm to guard against the hazards that co-developing knowledge involves, it should also be recognized that firms differ in their resources and that cooperation in $\mathrm{R} \& \mathrm{D}$ can provide more productive and complementary resources as well as valuable opportunities for learning. Universities are by definition science-oriented, and their contribution is useful in developing knowledge. Firms possess application-oriented capabilities that are used at the end of the project to complement the first -initial- phases of development.

Figure 2. R\&D project organization

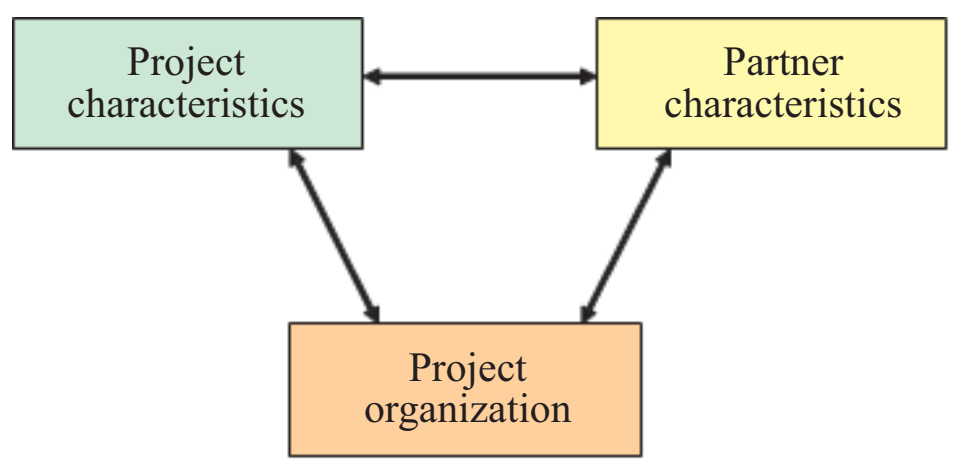


In sum, we found that when "opening the black box" of the open innovation process, it is important to emphasize the relationship between knowledge attributes, partner characteristics and organization (see Figure 2).

\section{Innovation at the activity level}

An open innovation process is composed of a series of interconnected decisions at the project and at the activity level. Ultimately, as every project manager knows, organizing a project means organizing its single constituent activities. Specifically, this has to account for how activities within the research project are led, i.e. who is in charge of accomplishing them. Therefore, to further analyze the role of different partners, we checked which activities companies and universities were most likely to lead in projects in which they were formal partners of ST.

Given a general, average project carried out in cooperation, two dimensions stand out as relevant in the decision on which external partner to choose: 1) the degree to which an activity is aimed at developing new knowledge (as opposed to applying prior knowledge), and 2) the position of the activity within the sequence of activities constituting the project, i.e. initial development activities versus later stage application activities. In essence, therefore, who you partner with depends on what you want to do and when you want to do it. What you want to do defines the capabilities and skills you potentially need. When you want to do it defines the risks and opportunities involved in the activity.

Our results highlight that university capabilities are more useful in the initial phases of a project, in particular when new knowledge has to be developed. Success requires a balance between exploiting old paths and exploring new ones. This is true within projects and across projects. To explore means to take risks, and it implies the need for new and different capabilities. Universities are at the cutting edge of research. A revolutionary project is characterized by initial activities that develop new knowledge: universities may boost this process. By cooperating with universities, companies can both share the risk of an uncertain result and reduce the risk of expropriation of value.

Most experts maintain that the success of a project is rooted in its early phases. These are phases in which the bases for the new technology are defined, where fundamental decisions are taken that will influence the whole course of the project. Companies may therefore be reluctant to expose themselves to the risk of opportunistic behavior by potential partners. On the other hand, when the later activities of a project require applied abilities and the need to experiment with the knowledge previously developed, firms may be the ideal partners. Not only does this reflect the nature of a particular industry technological practice we have already discussed (system-on-chip), but also the fact that firms possess specific skills and may be the potential customer of the final commercial application of the current project. Their participation may thus suggest specific needs at a very early stage, or particular constraints, or provide complementary capabilities.

In sum then, the first relevant dimension for organizational decisions is in what phase the activity is performed (whether it is at an early stage of the project or not). In the first phases of the project, firms are more likely to collaborate with universities, whereas toward the end of the project the reference counterpart is more often another firm. The second dimension is basicness, i.e. the closeness to basic research. Universities are involved in activities in which new knowledge is developed, and firms are significantly more likely to be involved in activities in the later phases of the project. The analysis suggests that 
universities are chosen for their capabilities in basic research, whereas firms are sought in the terminal part of low basic research activities to provide complementary capabilities in the application/ experimentation of the knowledge previously developed. Activities characterized by less codified knowledge and in the early phase of a project are conducted primarily internally.

\section{Project performance: a multidimensional construct}

Ultimately, firms are concerned about performance. The natural next step in our analysis is to identify the consequences of different organizational forms for performance.

Analyzing the projects in our sample, two immediate conclusions leap out. First, project performance is a multidimensional construct. ${ }^{19}$ While one dimension of performance captures the extent to which a project has been efficient (e.g., the project was on time, within budget, etc.), the other dimension depicts the learning opportunities the project offered (e.g., new opportunities were discovered, new knowledge was acquired). Second, a project's organization seems to have an impact on these different dimensions. In particular, simply looking at average differences in performance, cooperation has a generally negative effect on efficiency. Results on learning are less clear-cut, but still hint at a negative effect of cooperation, in particular when the cooperation is carried out with a firm.

Should we conclude that spanning the boundaries of the firm when organizing $R \& D$ projects has a negative effect on performance? Why is it that a company well known for its history of successful technological cooperation actually perceives a negative utility of spanning its boundaries at the project level?

Undoubtedly, the general negative effect of cooperation may be due to some organizational disruptions, which are frequent in such agreements. However, the negative correlation between project performance and cooperation may also be the outcome of a more complex mechanism. To understand the effect of organization on performance, we need to gain a deeper understanding of the process through which this may take place.

In this study, we conjecture that project performance is a function of:

a) the effort the team puts into the project,

b) the intrinsic characteristics of the project (which may make the same level of effort more or less productive), and

c) the project's organization.

Still, the organizational form of a project is not decided independently of its characteristics. The optimal organizational form for a project is chosen on the basis of the project's specific characteristics (see Figure 3). It may then well be that some projects are outperformed by others because of their specific characteristics, which may make them inherently more difficult to carry out. If these characteristics also increase the propensity to cooperate, we may be driven to the wrong conclusion that cooperation worsens performance. The same can be said for variables influencing the exerted effort. We could argue, for instance, that the strategic importance of the project has a positive effect on the

\footnotetext{
${ }^{19}$ Several statistical indicators, such as correlation coefficients between items, principal component analysis and Cronbach's alpha coefficients, concur to clearly indicate that two dimensions of project performance are observed.
} 
effort exerted and thus on performance. However, the strategic importance of the project also increases the chances of opportunistic behavior of a potential partner, and thus -as we saw- decreases the propensity to cooperate. Therefore, we observe that projects conducted in cooperation present worse performance results on average. But this result may be driven purely by a lower effort and strategic importance of cooperative projects.

Figure 3. Drivers of R\&D project performance

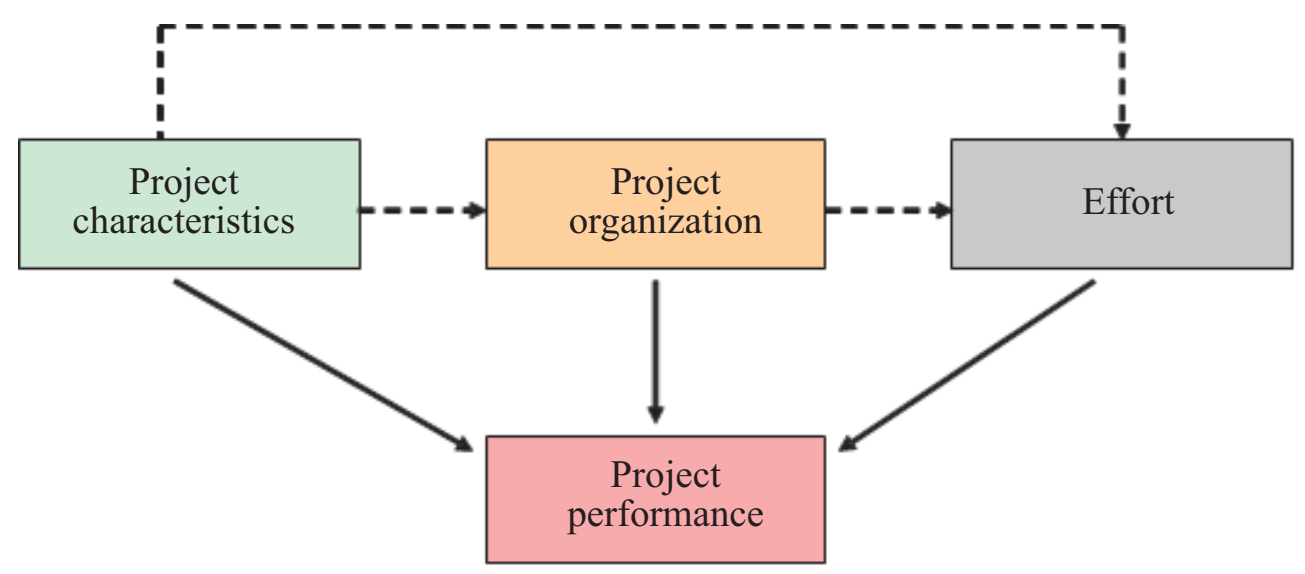

While a full econometric analysis of the endogenous relationship between organization and performance is beyond the scope of this paper, we believe that there are still some interesting lessons to be learned. To begin with, the fact that performance is a multidimensional construct points not only to the well known necessary balance between long term and short term, or exploration and exploitation, but also to how firms should decide resources and incentives for project managers to weigh up efficiency and learning. If project managers are rewarded purely on the basis of efficiency, then learning will necessarily be overlooked. On the other hand, efficiency is the only "observable" outcome, in that it is difficult to objectively assess how much was learned during a project.

What solution does ST adopt? First, it uses a balanced set of performance indicators, which varies across projects and R\&D tiers, weighting efficiency and formalized measures more heavily in more applied projects and activities. Second, and more importantly from an innovation strategy perspective, ST carefully selects its portfolio of projects. By committing to the execution of some types of projects, ST may assure some level of learning - at the firm level. As argued, the selected project characteristics lead to a specific project organization, spanning the boundaries of the organization, implying a higher degree of openness and learning.

Moreover, it is impossible to draw unconditional lessons about the impact of an open innovation strategy. The value created by an open innovation strategy is contingent upon the situation. Opening the boundaries of innovation may even appear to have a negative impact on performance. However, the performance of a given project should be compared to the performance that same project would have had, had cooperation not occurred. Therefore, if projects carried out in cooperation differ systematically from those developed fully internally, then simply comparing "open" and "closed" projects may lead to erroneous conclusions. Finally, not only does organization have a direct effect on performance, but also an indirect effect via researchers' effort. Different organizational forms may have different effects on the incentives researchers have to perform. 


\section{Conclusion}

The managerial messages that emerge from this study are the following.

- Make the organization of $R \& D$ projects conditional on the features of the knowledge they involve. ST's experience shows that partnering or contracting with universities for innovation is common practice for developing new -originalknowledge, as opposed to applying existing knowledge to a problem. But the firm is more reluctant to partner, especially with another firm, when this knowledge is of strategic importance. The risk of opportunistic behavior is the proposed rationale behind this choice.

- Appreciate the different dimensions of project performance. Project performance is a multidimensional construct. One dimension picks up project efficiency and immediate benefits (e.g. tasks are accomplished, project is on budget), while the other includes learning and long-term benefits (e.g. new applications are discovered, new capabilities are acquired). Therefore, efficiency and costminimization are surely important objectives, but learning and developing capabilities are an equally relevant concern.

- Commit to learning through project selection and open innovation. While spanning the boundaries of the firm for innovation does not seem to have appreciable effects on perceived project efficiency, it nonetheless brings about intertemporal benefits related to learning and capabilities development. In a dynamic environment, building knowledge may be more important than protecting it. Thus, under certain conditions, an open innovation process may be an exceptionally effective way to build and develop firms' technological future.

Finally, we also need to highlight an important limitation of our study: the nature and size of our sample can only provide preliminary and exploratory results. Although this study clearly has the potential for application in other settings, the results may not be readily generalizable. However, given our research design, we were able to obtain exceptionally fine-grained data, sacrificing quantity for quality. Furthermore, analyzing the case of one single firm automatically controls for a series of other effects, which are difficult to capture and may have an influence on innovation strategy and R\&D organization. This makes it possible to focus on the only relevant dimension left: the project features. 